\section{Comunicação e saúde mental: análise discursiva de cartazes do Movimento Nacional de Luta Antimanicomial do Brasil}

\section{Communication and mental health: a discursive analysis of posters of the National Anti-Asylum Campaign Movement in Brazil}

\section{Wanda Espirito Santo}

Pesquisadora, Laboratório de Estudos e Pesquisas em Saúde Mental e Atenção Psicossocial (Laps)/Fiocruz.

wanda.santo@ensp.fiocruz.br

\author{
Inesita Soares de Araujo \\ Pesquisadora, Laps/Fiocruz. \\ inesita@icict.fiocruz.br
}

\section{Paulo Amarante}

Pesquisador, Laps/Fiocruz.

pauloamarante@ensp.fiocruz.br

Laps/Fiocruz.

Prédio da Expansão

Avenida Brasil, 4.036, sala 506

21040-361 - Rio de Janeiro - RJ - Brasil
SANTO, Wanda Espirito; ARAUJO, Inesita Soares de; AMARANTE, Paulo. Comunicação e saúde mental: análise discursiva de cartazes do Movimento Nacional de Luta Antimanicomial do Brasil. História, Ciências, Saúde Manguinhos, Rio de Janeiro, v.23, n.2, abr.-jun. 2016, p.453-471.

\section{Resumo}

Analisa dois cartazes que, com o mesmo slogan - "Manicômio nunca mais" -, divulgam o Dia Nacional da Luta Antimanicomial. Baseia-se em fundamentos da semiologia dos discursos sociais, articulando conceitos e práticas analíticas advindos da escola francesa e da vertente pragmática da análise de discursos. Seus resultados mostraram estratégias de afirmação do movimento pela qualificação e exacerbação dos sujeitos da enunciação e outros enunciadores - atores políticos do movimento antimanicomial e seus aliados - e desqualificação do discurso concorrente, principalmente pela evidenciação dos graves problemas de suas matrizes institucionais, mas também pela contraposição à presença positiva dos emissores e enunciadores dos cartazes.

Palavras-chave: movimentos sociais em saúde; comunicação e saúde; luta antimanicomial; análise de discursos.

\section{Abstract}

The article analyzes two posters that with the same slogan - "Asylums nevermore" - promote National Anti-Asylum Day. The analysis was based on principles of the symptomatology of social discourse, articulating analytical concepts and practices arising from the French School and the pragmatic dimension of discourse analysis. The results revealed affirmation strategies of the movement for the qualification and exacerbation of the issues of the enunciation and other enunciators, namely political actors of the anti-asylum movement and their allies. It also reveals the attempt to disqualify competitive discourse, especially that which discloses the serious problems of its institutional models, but also by juxtaposing the positive presence of the issuers and enunciators of the posters.

Keywords: social movements in health; communication and health; anti-asylum campaign; discourse analysis. 
$\mathrm{A}$ luta por uma sociedade sem manicômios é uma das mais bem sucedidas da história recente brasileira. Uma das principais práticas de visibilidade do movimento é a comemoração do Dia Nacional de Luta Antimanicomial, sendo a data lembrada em diversas localidades do Brasil. As comemorações desse dia têm nos cartazes uma das suas principais estratégias de divulgação e mobilização: com eles circulam e são difundidos os discursos que defendem uma sociedade sem manicômios.

A leitura analítica e comparativa de dois cartazes comemorativos desse dia nos conduzirá e permitirá compreender algumas estratégias discursivas do Movimento Nacional de Luta Antimanicomial no Brasil. ${ }^{1}$ Os cartazes selecionados como corpus de análise para este artigo foram coletados no Laboratório de Estudos e Pesquisas em Saúde Mental e Atenção Psicossocial/ Escola Nacional de Saúde Pública Sergio Arouca/Fundação Oswaldo Cruz (Laps/Ensp/Fiocruz), onde se encontra um vasto acervo desses materiais que narra a trajetória antimanicomial no Brasil.

A escolha ocorreu a partir do uso do mesmo enunciado em momentos e localidades diferentes. Os discursos apresentados nos cartazes foram observados levando em conta que os materiais, sendo produzidos em determinados contextos históricos, são influenciados pelos dilemas e contradições de seu tempo, na mesma medida em que procuram construir uma nova realidade.

Optamos por tomar como principal suporte teórico a semiologia dos discursos sociais tal como proposta por Pinto (1994), que concilia aportes da escola francesa de análise de discursos e da pragmática, e cujos conceitos foram articulados conforme as necessidades específicas de análise apontadas pelo corpus.

Iniciaremos com uma visita ao Movimento Nacional de Luta Antimanicomial (MNLA), na sequência faremos uma breve exposição sobre os princípios semiológicos que norteiam a abordagem analítica e metodológica, para então proceder à análise propriamente dita.

\section{Movimento Nacional de Luta Antimanicomial}

A cidadania, como experiência histórica, é capaz de sofrer reformulações. O que nos permite entender que as questões relacionadas aos direitos precisam ser constantemente relocalizadas na esfera pública e fazer parte dos debates e das relações políticas. Ao interrogar os limites entre os direitos e as práticas sociais, encontramos a luta antimanicomial.

São diversos os autores que discutem a reforma psiquiátrica brasileira, tais como: Amarante (2013); Vasconcelos (2012); Scarcelli (2011); Pitta (2011); Yasui (2010); e Desviat (2008). Para compreendê-la, visitaremos os seus primórdios.

No Brasil, o Movimento dos Trabalhadores em Saúde Mental (MTSM) surgiu na década de 1970, em importante momento histórico nacional. O ano de 1974 foi marcado por uma esmagadora vitória da oposição nas eleições parlamentares, os votos de protesto contra o regime militar caracterizaram o fim do milagre econômico e a retomada da luta pelo Estado de Direito (Nunes, Jacobi, 1983).

O MTSM materializou, naquele momento, graves denúncias contra o sistema nacional de assistência psiquiátrica, acusações que foram acompanhadas de mobilizações por projetos alternativos ao modelo asilar dominante e a efetivação de um pensamento crítico sobre as 
práticas psiquiátricas (Amarante, 2013). A efervescência da época alimentava os movimentos do setor de saúde. Yasui (2010) e Amarante (2013) enfatizam, em seus trabalhos, a articulação da luta da saúde mental com o Movimento da Reforma Sanitária e entidades como o Centro Brasileiro de Estudos de Saúde.

Em 1986 ocorreu a Oitava Conferência Nacional de Saúde, e, em sequência, em 1987, a Primeira Conferência Nacional de Saúde Mental. O processo, que culminou na Constituição de 1988 e conduziu à afirmação e ao reconhecimento de direitos, refletindo o desejo da sociedade brasileira de romper com as práticas arcaicas, foi traçado por uma participação política ativa. Vasconcelos (2012) comenta que ocorreu um importante acúmulo de forças que tornaram possíveis os avanços significativos da Constituição Federal de 1988. Os insumos vindos da Europa alimentaram os ideais reformistas desde a década de 1970, e teóricos ativistas como Franco Basaglia, Michel Foucault, Ronald Laing, Felix Guattari e Robert Castel participavam de eventos diversos no Brasil (Pitta, 2011). Destacou-se a Rede Internacional de Alternativas à Psiquiatria fundada em Bruxelas, em 1975, que, sendo contemporânea do Movimento de Psiquiatria Democrática, nasceu da necessidade de uma troca entre experiências que estavam em andamento naquele momento (Elkaim, 1977). A rede, composta de personalidades de diversas áreas, expandiu-se para a América Latina, e suas ideias ganharam força no Brasil.

O Segundo Congresso de Trabalhadores de Saúde Mental, ocorrido em 1987, em Bauru, São Paulo, acompanhou tais rompimentos, distinguindo-se com especial importância para a compreensão dos cartazes que serão aqui analisados. Dos acontecimentos que fizeram do congresso de Bauru um momento emblemático, vale a pena citar a criação do MNLA, a inclusão em suas discussões dos usuários e suas famílias (Amarante, 2013) e o estabelecimento de 18 de maio como Dia Nacional da Luta Antimanicomial, este último relacionado aos objetivos do presente trabalho.

Pitta (2011) comenta experiências inovadoras que foram ocorrendo em diversos locais do Brasil, desde a década de 1970. Um novo tipo de cuidado foi-se arquitetando. Vasconcelos (2012, p.174) destaca a substituição gradual do "modelo de atenção e gestão em saúde mental", Amarante (2013) ressalta a importância de experiências como o Centro de Atenção Psicossocial (Caps) Luiz Cerqueira da Rocha, na cidade de São Paulo, fundado em 1987, e a intervenção na casa de Saúde Anchieta, em Santos, em 1989.

Também em 1989, o deputado Paulo Delgado (Partido dos Trabalhadores-Minas Gerais) apresentou o projeto de lei n.3.657/89, que ficou conhecido como Projeto Paulo Delgado. Com três artigos estruturantes, o projeto regulamentava a extinção gradual dos manicômios, os direitos do doente mental e a criação de recursos substitutivos ao tratamento manicomial. Aprovado na Câmara dos Deputados, teve sucessivas postergações e substitutivos no Senado, sendo homologado em 2001 pelo presidente da República, convertendo-se na lei n.10.216/2001. Nos anos de tramitação foram formulados e aprovados diversos projetos de lei similares, estaduais e municipais pelo Brasil (Santoro Filho, 2012), além de ocorrer a instauração das portarias do n.189/91 até o n.224/92, do Ministério da Saúde, que possibilitou que o Sistema Único de Saúde (SUS) financiasse outros procedimentos assistenciais diferentes do leito e da consulta ambulatorial (Amarante, 1995). No início dos anos 1990, como assinalado por Maia e Fernandes (2002), os representantes administrativos do Estado 
se posicionaram a favor da inversão do tratamento hospitalar para o atendimento que privilegiasse a não internação. O Ministério da Saúde não concordou com os pedidos de aumento do número de leitos manicomiais, as inspeções sanitárias do governo estadual foram intensificadas, as investigações de denúncias variadas, tais como maus-tratos, superlotação, cela-forte e outras, tornaram-se mais frequentes. Em 1992, o Ministério da Saúde marcou sua posição com a campanha "Doença mental não é crime". Segundo os autores, os agentes governamentais, ao se posicionar pela extinção dos manicômios, criaram forte atrito com os proprietários de clínicas privadas e hospitais conveniados. Maia e Fernandes (2002) explicam que, quando a polêmica se acirrou, os proprietários, em vez de afirmar o valor do atendimento hospitalar, preferiram utilizar lobbies junto ao Congresso. A Federação Brasileira de Hospitais - entidade representante dos donos de hospitais particulares -, em 1991, por meio de abaixo-assinado, conseguiu que as votações do Projeto Paulo Delgado fossem adiadas diversas vezes. Na ocasião, o Ministério da Saúde, representado pelo ministro Adib Jatene, colocou-se favorável à aprovação do projeto. Em dezembro de 1992, ocorreu a Segunda Conferência Nacional de Saúde Mental, com expressiva participação de usuários e familiares, além de gestores, trabalhadores, políticos e outros setores da sociedade. Ao final, de acordo com Yasui (2010), foi produzido um relatório extenso e específico sobre as questões da saúde mental, com poucas citações ao momento político em curso. Segundo Pitta (2011), o relatório desempenhou papel de diretriz oficial para a gestão de Domingos Sávio Alves, e as coordenações seguintes de saúde mental no Ministério da Saúde. De fato, como esclarece Yasui (2010), muitas propostas apresentadas se concretizaram. O autor cita, por exemplo, a criação da Comissão Nacional de Reforma Psiquiátrica em 1993.

O Primeiro Encontro Nacional da Luta Antimanicomial realizou-se em 1993, na cidade de Salvador, na Bahia, e ratificou a identidade do movimento. De caráter apartidário, porém político, sua militância se organizava em núcleos articulados nacionalmente, mas que, de forma descentralizada, compunham uma rede (Soalheiro, 2003).

Os dez anos de luta antimanicomial foram comemorados em 1997. Além dessa celebração, ocorreu o Terceiro Encontro da Luta Antimanicomial em Porto Alegre, Rio Grande do Sul. No evento, denominado "Por uma sociedade sem exclusões", destaca-se a preocupação com a inserção do usuário na sociedade, estabelecida em uma proposta visando superar as dificuldades de moradia e manutenção dos ex-internos dos hospitais psiquiátricos por meio de lares abrigados e pensões protegidas (Maia, Fernandes, 2002). Segundo os autores, os representantes do movimento, ao enfocar a necessidade da desospitalização e fazer a defesa de uma rede substitutiva como a melhor forma de atendimento, não perderam de vista a importância da qualidade oferecida no novo modelo.

Em 1999, o projeto de lei n.3.657 saiu do Senado e retomou a tramitação na Câmara; no mesmo ano, foram liberados recursos para quatrocentos Caps e incentivo-bônus para a desinstitucionalização (Pitta, 2011). Os anos 2000 trouxeram avanços normativos importantes para a reforma psiquiátrica brasileira. Em 6 de abril de 2001, o Congresso Nacional decretou e a Presidência da República sancionou a lei n.10.216, que ficou conhecida como a Lei da Reforma Psiquiátrica Brasileira. A aprovação ocorreu na forma de um substitutivo do Projeto de Lei Paulo Delgado, que, em seu formato original, tramitou por 12 anos no Congresso Nacional. A lei dispõe sobre a proteção e os direitos das pessoas com transtorno mental, 
redireciona o modelo assistencial oferecendo preferencialmente serviços de base comunitária para o tratamento do transtorno mental, mas não institui mecanismos precisos direcionados à progressiva extinção dos manicômios.

Realizado em outubro de 2001, o Quinto Encontro Nacional do Movimento da Luta Antimanicomial trouxe o lema "Como estamos? O que queremos? Para onde vamos?". Durante a plenária final, as discussões relacionadas à organização do movimento apresentavam proposições excludentes entre si. O grupo que acreditava na formação de núcleos para promover a articulação e facilitar a circulação de informações tornou-se, após o rompimento, a Rede Nacional Internúcleos de Luta Antimanicomial, constituída em 2003 a partir de uma decisão coletiva. O MNLA empenhava-se na "defesa de projetos e serviços inovadores de base local e ... organização de base de empoderamento dos usuários e familiares contra formas de aparelhamento, politização e centralização excessivas e verticalizadas" (Vasconcelos, 2012, p.60).

Em 2002, uma série de normatizações do Ministério da Saúde instituiu mecanismos para a redução de leitos psiquiátricos em todo o Brasil. Não se deve, porém, desconsiderar que as mudanças ocorreram de forma diferente em cada região do Brasil e dependeram da pactuação realizada entre as três esferas do governo e da aceitação das transformações localmente. Há que destacar o Programa Nacional de Avaliação do Sistema Hospitalar/Psiquiatria, o Programa Anual de Reconstrução da Assistência Hospitalar Psiquiátrica no SUS e o Programa de Volta para Casa (Reforma Psiquiátrica e Política de Saúde Mental no Brasil).

A luta antimanicomial, apesar de todas as cisões e das disputas internas, tem determinado os rumos da reforma psiquiátrica brasileira (Pitta, 2011). Ao promover a circulação de informações nos mais diversificados cantos do Brasil, conseguiu que seus participantes compartilhassem uma mesma economia emocional, criando um sentimento de pertencimento tão desejado e fazendo com que os interessados se tornassem protagonistas de suas próprias lutas.

\section{Nos caminhos semiológicos}

O percurso da semiologia reabilita o lado humano e histórico da linguagem, faz com que ela se inscreva em múltiplos universos e acompanhe importantes disciplinas do saber contemporâneo, principalmente as relacionadas às ciências sociais e humanas. A semiologia é "uma ciência em constante transformação e construída historicamente no bojo dos movimentos de crítica e contestação" (Araújo, 2000, p.116).

A semiologia, como termo médico, está relacionada ao estudo dos sinais e sintomas das doenças em geral. No âmbito das ciências das linguagens, pode ser conceituada como a ciência que estuda os fenômenos de produção social dos sentidos. Há modos diferentes de entender esse fenômeno, mas todos convergem para a ideia de que ele é essencialmente da ordem dos discursos sociais. Também é consenso entre as várias abordagens a premissa de que os discursos constituem os sentidos dos seus referentes, portanto, constituem os referentes, advindo daí a noção de prática discursiva (Foucault, 2009; Pinto, 1994).

A semiologia está, sendo assim, identificada metodologicamente com a análise de discurso (AD). Há modos distintos de entender e praticar a $\mathrm{AD}$, sendo que, de modo geral, eles se 
filiam a duas matrizes: à tradição francesa, que privilegia as noções de história e ideologia, e à escola anglo-saxã, baseada sobretudo na pragmática, que privilegia a noção de contexto.

Adotamos uma terceira via, a da análise de discursos sociais (ADS), proposta por Pinto (1994), que buscou articular, na prática analítica, elementos conceituais das duas matrizes. O caminho semiológico inclui conceitos que nos permitem avançar no conhecimento dos materiais que serão estudados, esmiuçar seus fragmentos, desvelar os dispositivos de enunciação, favorecendo assim maior aproximação aos sentidos propostos nos cartazes. Destacaremos alguns conceitos incorporados pela ADS de modo apermitir a compreensão da análise procedida nos cartazes.

Como afirmado, um dos conceitos fundamentais da semiologia é o da produção social dos sentidos. Para a escola francesa de AD, essa produção ocorre principalmente nas formações discursivas: ali, as palavras adquirem sentido e o sujeito ganha identidade. Orlandi (2008, p.58) explica que o sentido "não existe em si, mas é determinado pelas posições ideológicas colocadas em cena no processo sócio-histórico em que as palavras são produzidas".

A autora apresenta duas instâncias de constituição do discurso: a enunciação e o enunciado. Se a enunciação ocorre no contexto sócio-histórico, é da instância do repetível e é do domínio do saber, podendo ser chamada de interdiscurso - aquele de que o sujeito se apodera ao produzir linguagem -, o enunciado é a instância na qual o sujeito intervém, instância do eu aqui e agora, podendo ser chamado de intradiscurso - projetado no espaço e tempo e orientado socialmente para o destinatário. Convive-se então com uma dupla determinação: externa (histórico-social) e interna (autonomia, responsabilidade).

Nessas instâncias, a fala do sujeito não apenas acusa um grau de intencionalidade, mas está envolta em discursos constituídos historicamente e produzidos a partir de um lugar social, ideológico. Na fala do sujeito, outras falas se fazem presente; assim, um texto é sempre uma superfície discursiva heterogênea.

Nesse ponto e nessa perspectiva, o pensamento bakhtiniano mostra-se de importância fundamental. Produzido em círculos de discussões na Rússia entre os anos de 1920 e 1970, constituído pelos escritos de Mikhail Mikhálovich Bakhtin (1895-1975), de alguns colegas do círculo e de discípulos, provocou grande impacto na semiologia francesa e nos estudos de linguagem, ao resgatar a importância da fala como objeto de atenção e estudo e propor os conceitos de polifonia e dialogismo. O enunciado torna-se um ato histórico, único e não repetível. Bakhtin (2006) o observa como um acontecimento que tem no Outro um papel fundamental, uma vez que ele não pode ser dissociado do sujeito. Toda enunciação é resposta a alguma coisa, prolonga e polemiza com as que a precederam. A enunciação é socialmente dirigida, o meio social que envolve o indivíduo destaca-se como centro enunciador. Assim, a existência da linguagem está relacionada a um complexo sistema de diálogos que nunca termina, e a enunciação é um elo na cadeia de falas.

O conceito bakhtiniano de dialogismo, presente em toda obra de Bakhtin desde Marxismo e filosofia da linguagem, de 1929 (assinado Voloshinov), que referencia os modos específicos de articulação das diversas vozes do texto, conversa teoricamente com o conceito de semiose infinita (Peirce, 1977) que nos fala das remissivas de significantes a significantes que se observam no processo de produção dos sentidos, criando um diálogo contínuo, no qual objetos, textos, enunciados e discursos podem adquirir inúmeros sentidos - por vezes, contraditórios. 
Pinto (1994), comentando a semiose na moderna semiologia, lembra que, numa cultura, todos os objetos são revestidos de sentido; dessa forma, objetos significantes que foram relacionados culturalmente formam uma cadeia de interpretantes. Ao infinito, eles se vão remetendo uns aos outros. O processo trabalha com "remissivas de significante a significante, produzindo efeitos de sentido", que, na atualidade, recebem o nome de intertextualidade (Pinto, 1994, p.14).

Maingueneau (2006, p.78) assinala, entre os fatores de heterogeneidade, "a presença de discursos 'outros' num discurso". Araújo (2000), seguindo a linha analítica de Verón (1980), ressalta que nas marcas do sujeito da enunciação estão as imagens que o emissor tem de si ou aquelas que ele quer vincular a si, daqueles a quem destina seu discurso, demais agentes sociais e relações que estabelecem uns com os outros.

Os sujeitos estão presentes e se constituem nos textos de várias e distintas formas discursivas. Autores divergem quanto à sua classificação, mas podemos considerar que são variações em torno do mesmo tema. Aqui adotaremos a seguinte modalidade, baseados em Araújo (2002), que, por sua vez, toma como ponto de partida Pinto (1994): (a) emissores são aqueles que assumem a autoria material do texto em análise; (b) sujeitos da enunciação são construídos discursivamente e podem ou não coincidir com os emissores. É quem de fato "fala" no texto, quem assume o protagonismo e conduz a narrativa; (c) enunciadores são todos aqueles cujas vozes são convocadas pelo sujeito da enunciação, em geral como forma de legitimação deste, mas, pelo próprio princípio discursivo da não autonomia total sobre a autoria do texto, também podem produzir outros sentidos que não o de legitimação; (d) estão incluídos nesta última categoria aqueles que fazem circular um discurso concorrente ao do movimento antimanicomial, mas que não são admitidos como enunciadores. Estão presentes nas marcas mobilizadas pelo emissor - palavras, imagens, expressões -, em geral num processo claro de concorrência. Aqui foram tratados separadamente dos enunciadores, sob a designação de discursos antagonistas.

$\mathrm{Na}$ análise dos cartazes, englobamos todos os sujeitos num mesmo tópico, denominado "os enunciadores", a partir de então separando pelas categorias aqui descritas.

Araújo (2002) comenta que há diversos modos de ver e nomear a realidade; assim, a percepção de uma mesma realidade é modelada de forma diferente por diferentes agentes sociais. A dominância dos sentidos é disputada entre as diversas comunidades discursivas (Maingueneau, 1997; Araújo, 2000), tornando os discursos concorrentes.

Verón (1980, p.189), cuja abordagem obriga a considerar a noção de contexto no processo analítico, comenta: "analisando produtos, visamos a processos". O autor trabalha com a hipótese de que o sistema produtivo deixa traços nos produtos, considerado o sistema produtivo como conjunto de coerções que, por serem diversas em sua origem e natureza, são heterogêneas. Encontrando-se as coerções (condições de produção), pode-se aventurar a uma aproximação à rede semiótica que, por sua vez, permite compreender os mecanismos de base do funcionamento social. Para Verón, então, o processo de análise semiótica privilegia as múltiplas condições de produção textual. Indo além e chegando no cerne de sua proposta, o trabalho social de investimento de sentido nos textos não pode ser desvinculado da ordem do ideológico (produção) e da ordem do poder (consumo/reconhecimento). 
A organização dos aspectos formais, incluindo imagem, texto, diagramação, escolha do meio de comunicação, formato do material e das formas de circulação, é parte dos dispositivos de enunciação. Mas tudo aquilo que foi excluído pelo sujeito enunciador também participa dos dispositivos. O que foi preterido se torna um fantasma do que foi escolhido e, como excluído, participa dos efeitos de sentido (Orlandi, 2008).

Ainda com Verón (1980), podemos dizer que os dispositivos de enunciação atravessam o discurso e deixam marcas. São essas marcas que possibilitam ao receptor refazer as operações realizadas pelo emissor, dessa forma participando do processo de negociação dos sentidos. Para essa operação, o receptor, tanto quanto o emissor, se vale dos seus dispositivos, cujas diferenças são dadas pelas diferenças de posição social, interesses, cultura e outros fatores.

O que interessa ao analista é o modo como as marcas se manifestam no texto e lhe permitem chegar às propriedades do discurso. No entanto, ele não pode entender essas marcas fora das suas condições históricas, sociais, institucionais, materiais e mesmo subjetivas de produção, ou seja, os múltiplos contextos que possibilitaram a emersão daquele texto.

\section{Uma leitura dos cartazes}

A análise compara dois cartazes, ambos com o slogan "Manicômio nunca mais". Pelos objetivos deste trabalho, buscamos perceber quem são os atores políticos que se apresentam como enunciadores, quais os convocados para legitimar o enunciado, quais os discursos concorrentes e os dispositivos de concorrência. A identificação das condições de produção de cada peça de comunicação, tanto as de ordem institucional, política e histórica quanto as vinculadas aos contextos mais pragmáticos, é necessária para produzir um melhor entendimento da negociação discursiva. O histórico do movimento da luta antimanicomial, apresentado anteriormente, traz parte dessas condições. As demais podem ser inferidas a partir deste tópico e com base no conhecimento das práticas do movimento, assim como pelo próprio dispositivo, em alguns de seus elementos materiais.

As imagens dos cartazes estão reproduzidas a seguir. O cartaz 1 (Figura 1) circulou em 1997, foi produzido em Assis, São Paulo, e tem as dimensões $43 \mathrm{~cm}$ x $65 \mathrm{~cm}$. O cartaz 2 (Figura 2) não registra o ano de circulação, mas foi produzido em Minas Gerais e tem $40 \mathrm{~cm}$ x $60 \mathrm{~cm}$.

\section{Elementos gráficos significativos}

\section{Cartaz 1}

- Há um elemento visual em grande destaque - a foto de uma cela, parede branca, porta de grades fechada e dois homens nus, sentados com os rostos baixados. Os signos do manicômio são centrais no dispositivo de enunciação.

- O círculo carimbado com os dizeres "manicômios nunca mais" (no original, em vermelho) ocupa a parte superior direita da parede, sobrepondo-se visualmente aos signos manicomiais.

- Atos realizados no dia antimanicomial são informados com detalhe na coluna à direita. O contraste das letras brancas, no original sobre fundo vermelho, realça a informação.

- Apoiadores e realizadores constam no final dessa coluna. 


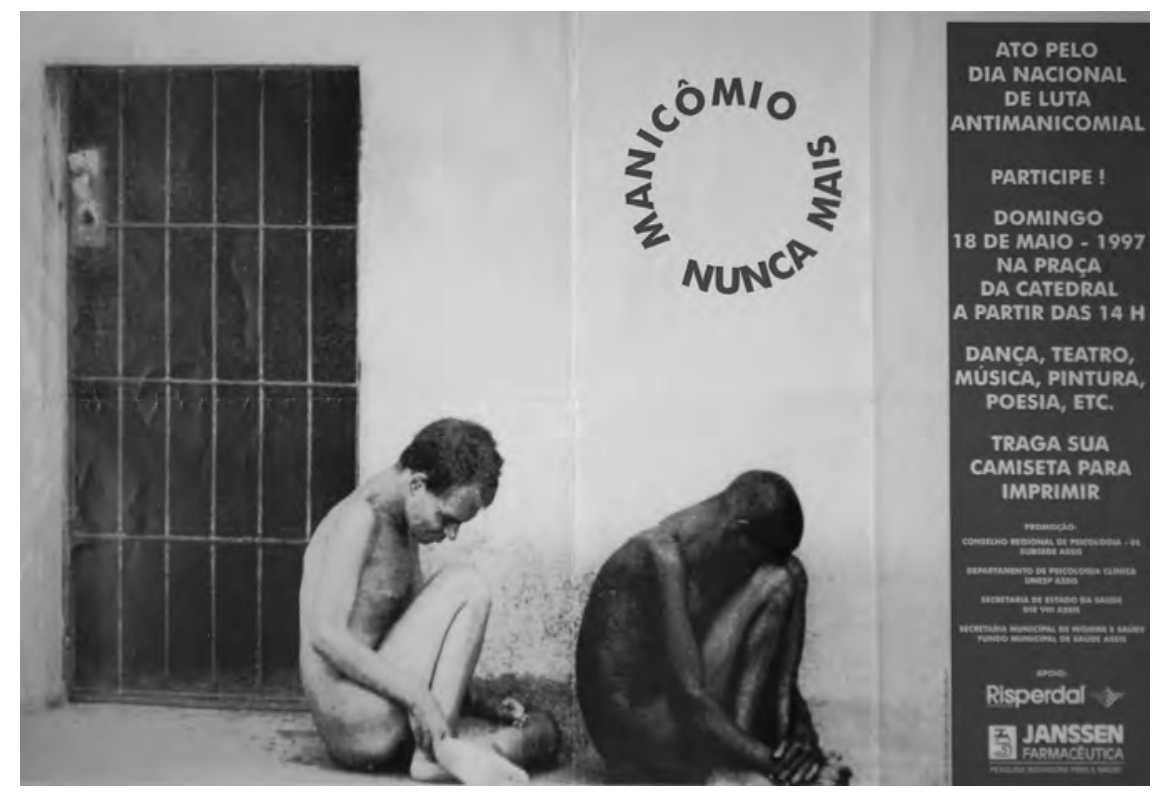

Figura 1: Fonte: Acervo Laps/ Ensp/Fiocruz.

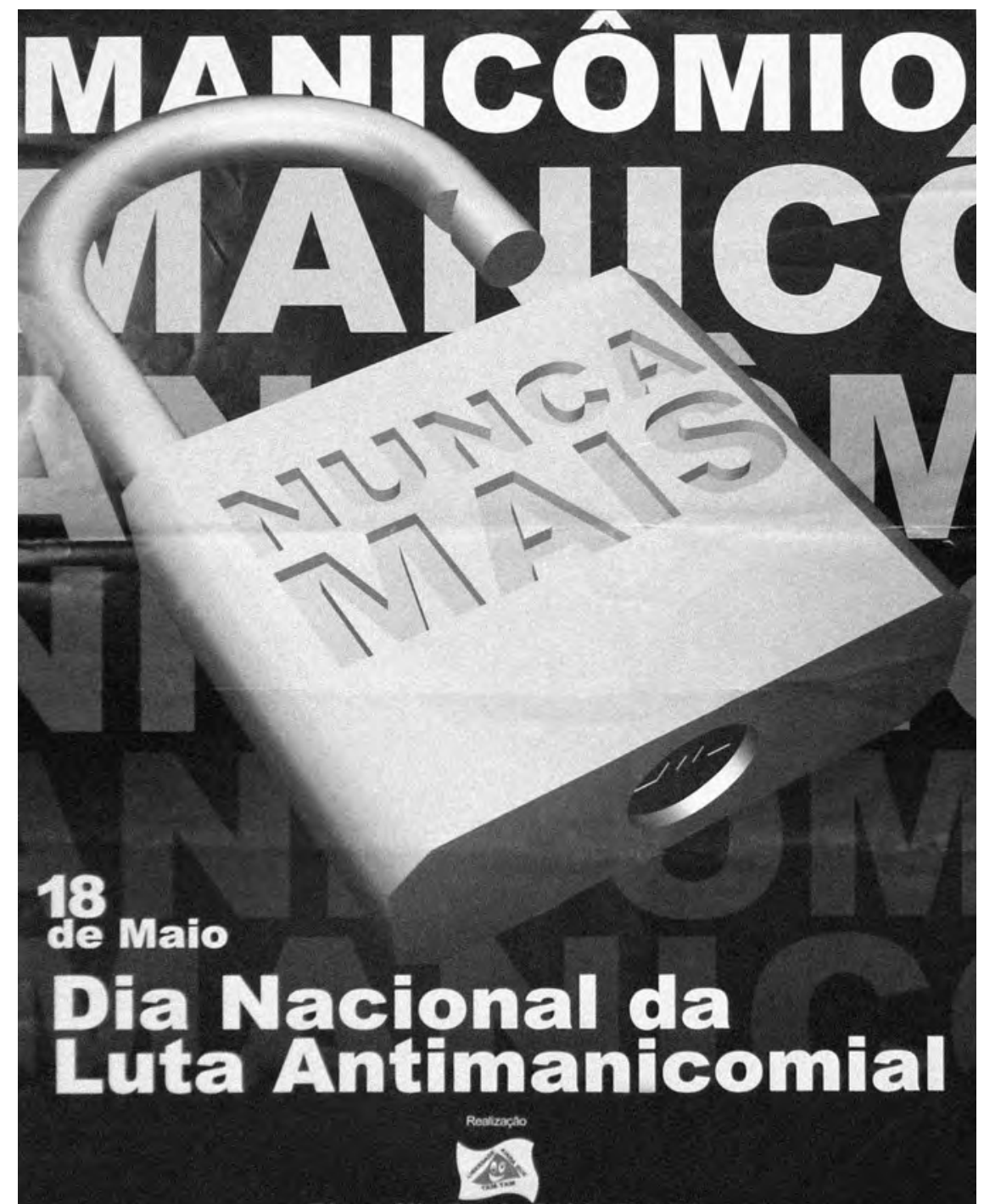

Figura 2: Fonte: Acervo Laps/ Ensp/Fiocruz.

Fórum Mineiro de Saúde Mental 
Cartaz 2

- Dois planos: no primeiro, um cadeado, no segundo, a palavra manicômio.

- Em destaque: um grande cadeado aberto escrito "nunca mais". A metáfora em primeiro plano confere centralidade ao slogan.

- A palavra manicômio vai desaparecendo gradativamente. A segunda palavra manicômio pode ser confundida com a palavra maluco, pois tem partes das letras escondidas pelo cadeado.

- Vinculada visualmente à imagem do cadeado aberto e se sobrepondo à palavra manicômio em diluição, aparecem os dados sobre o evento, acentuando sua motivação e sua afirmação positiva, de mudança em curso.

- Apoiadores e realizadores estão ao final do cartaz, mas centralizados.

\section{Os enunciadores}

Partimos do entendimento de que os atores sociais que produziram e fizeram circular os cartazes escolheram esse instrumento de comunicação como uma forma de intervir na realidade e produzir sentidos. Por outro lado, foram apoiados em seu intento. Utilizamos aqui o conceito de enunciador para englobar as três diferentes formas de constituição dos sujeitos discursivos: o emissor, o sujeito da enunciação e os enunciadores.

\section{Cartaz 1}

- Os emissores dos cartazes hibridizam-se com os sujeitos da enunciação, apresentandose como os promotores do evento, mas também assumindo-se como autores dos enunciados. São eles os representantes de classe (Conselho Regional de Psicologia, CRP), representantes do ensino superior (Universidade Estadual Paulista), o estado e o município, representados pelas secretarias de saúde.

- Outro enunciador, um laboratório farmacêutico, apresenta-se sob a designação de "promoção e apoio", forma de visibilidade que é naturalizada na prática de promoção de eventos, mas que discursivamente produz efeitos de sentidos até mesmo antagônicos. Essa forma de se apresentar institui um sujeito enunciador com presença forte no texto, mas também provoca potenciais efeitos de sentido que podem ser muito convenientes: o de certo distanciamento do ato enunciativo, um compromisso apenas secundário com o expresso no cartaz, mas também o de responsabilidade social, de benemerência.

- O fato de os emissores terem o apoio de um laboratório farmacêutico, por outro lado, imprime outras potencialidades discursivas ao cartaz. Pelo contexto das lutas históricas dos movimentos sociais contra a mercantilização da saúde e particularmente pela sabida postura da indústria farmacêutica de só se interessar pelo que é lucrativo, instaura-se um potencial efeito de sentido de que a indústria farmacêutica não se sente ameaçada pelo movimento de luta antimanicomial, até mesmo vislumbrando maiores lucros, assim como seu reverso, o de o movimento antimanicomial 
ter capitulado de suas lutas nesse aspecto. No entanto, essas são considerações que não poderão transformar-se em assertivas, uma vez que só um estudo de produção de sentidos em recepção é que poderia confirmá-las.

\section{Cartaz 2}

- Da mesma forma que no cartaz 1, o dispositivo discursivo do cartaz 2 constitui um sujeito da enunciação que também se apresenta como emissor. No plural, são o Fórum Mineiro de Saúde Mental e a Associação de Usuários que assumem o lugar de realizadores e, portanto, a autoria da iniciativa, comprometendo-se com suas premissas e bandeiras de luta.

- Como enunciador, vamos encontrar o CRP, que se apresenta como apoiador do evento, mantendo-se numa posição diferenciada em relação ao evento e às demais instituições. Esse é um dado relevante para o movimento: o fato de o apoiador ser o CRP $4^{\text {a }}$ Região nos informa que o movimento social tem respaldo dos trabalhadores de psicologia que atuam na área da saúde mental.

\section{Condições de produção}

Uma análise mais completa das condições de produção exigiria um aprofundamento da pesquisa que não foi possível fazer neste momento. Seguem algumas observações a partir do expresso nos cartazes, fundadas no nosso conhecimento prévio sobre as práticas do movimento.

\section{Cartaz 1}

- É possível perceber acordos que foram realizados para a produção do cartaz e do evento. A junção de forças acadêmicas, da gestão de saúde, classistas e da iniciativa privada farmacêutica apresenta segmentos que nem sempre trabalham em conjunto, que muitas vezes são forças antagônicas, mas que, no momento específico, se uniram com o mesmo objetivo. Pode-se dizer que, pelo seu antagonismo, objetivam ganhos diferentes.

- Considerando-se o habitual processo de decisão sobre a produção de peças comunicacionais nos movimentos sociais, os grupos envolvidos provavelmente se reuniram para escolher a forma de divulgação, quem seriam os responsáveis pela execução, quais eventos estariam relacionados à comemoração, como seriam divididos os gastos e tarefas. Pode-se constatar, pelo resultado, que houve uma hierarquização das forças presentes, orientada pelo aspecto funcional. A distribuição e a hierarquização gráfica dos elementos textuais do cartaz indicam que o processo seguiu a prática verificada nas relações institucionais: os representantes das instituições devem apoiar ideias que satisfaçam os hierarquicamente superiores. Esses e outros fatores afetam o discurso produzido e sua forma de circulação. 


\section{Cartaz 2}

- Percebe-se que há menos forças em conflito.

- A estrutura material parece ter sido bem mais modesta que a do cartaz 1, refletindose no resultado. Os seus realizadores não se destacam pelos recursos financeiros, e, apesar de envolvidos na mesma causa, a composição de suas organizações tem características diferentes. Havendo menos forças em conflito, devem posicionar-se de forma diferenciada dentro do movimento. Tomando por base nosso conhecimento dos contextos dos movimentos da saúde mental, podemos considerar que essas forças se reuniram para decidir o tipo de divulgação e talvez tenham se incumbido pessoalmente de sua execução e circulação. Os realizadores procuraram apoio no CRP $4^{\text {a }}$ Região, que também deve ter influído nas decisões tomadas e contribuído financeiramente ou com a impressão do cartaz. A falta de data nos dizeres é uma prática orientada pela economia de recursos, possibilitando que a peça seja usada em anos diferentes.

\section{Os discursos antagonistas e as estratégias de concorrência discursiva}

Os atores sociais da luta antimanicomial, com os cartazes, produzem sentidos para entrar no espaço social e disputar com outros atores o lugar de fala autorizada. Nos cartazes os discursos concorrentes não emergem de um sujeito institucional identificado, mas das estruturas que possibilitam a existência de manicômios. Emergem das imagens, certamente, mas também do texto, trazendo explicitamente suas palavras-chave para a superfície textual dos cartazes.

\section{Cartaz 1}

- O discurso antagonista é trazido para o cartaz por meio de uma imagem semantizada socialmente com signos dos maus-tratos, da violência contra quem está fragilizado e em sofrimento. Traz também para a memória discursiva de quem acompanha de algum modo a temática da saúde mental (por profissão, vivência pessoal ou familiar, filmes e outros meios de comunicação etc.) a desumanização completa dos manicômios, traduzida na nudez e na posição indefesa e humilhada dos seres humanos retratados. A imagem se transforma em discurso argumentativo, principal recurso do dispositivo de concorrência simbólica, ao ser associada visualmente, por contiguidade espacial, ao carimbo como slogan do movimento. Um slogan afirmativo e investido de força de lei pela analogia com o "cumpra-se" evocado pelo carimbo.

\section{Cartaz 2}

- A principal estratégia de concorrência é sobrepor o signo da libertação - o cadeado rompido - à palavra que identifica direta e concisamente a maior expressão material do sistema que se combate: o manicômio. O esmaecimento gradual da palavra, contundentemente substituída pelo cadeado rompido, tanto preconiza como aponta para mudanças que já vinham ocorrendo, buscando sua consolidação e instituindo o dia 18 de maio como momento de comemoração, mas também de luta. 


\section{A relação com os destinatários}

Cartazes são um gênero de material de comunicação por natureza destinado a um grande número de pessoas, que não se pode estabelecer quem são. Mesmo que circulem apenas em determinados ambientes (por exemplo, uma escola de medicina, ou um hospital), não se pode assegurar quem serão seus leitores. Então, em princípio, o próprio gênero já define que os destinatários são a população em geral. No entanto, pode-se inferir, por algumas condições de produção, que leitores são desejados, numa relação que se aproximaria mais de uma interlocução. Ou seja, o cartaz seria apenas um elo a mais em uma conversação que não começaria com ele nem com ele se encerraria.

Outra ressalva importante é que a noção de efeitos de sentido adquire sua máxima expressão quando estamos falando da relação com o Outro receptor. Os efeitos de sentido dizem respeito sempre ao modo como cada leitor processa os elementos constitutivos do texto em pauta (Araújo, 2000). Não há como produzir esse conhecimento de modo mais consistente a não ser em um estudo de campo, o que, neste caso, se torna impossível, por ser um material de épocas passadas. No entanto, nosso lugar de leitura (Landowski, 1992), marcado tanto pelo conhecimento profissional como científico, permite-nos tecer algumas possibilidades relacionadas à relação do emissor com os receptores dos cartazes. O analista é sempre um leitor, e todas as premissas discursivas aplicam-se a ele, em primeiro lugar.

Isso posto, vejamos algumas peculiaridades do dispositivo de cada cartaz.

\section{Cartaz 1}

- Não especifica destinatários, o que torna a convocação para o ato público, num espaço público, uma estratégia de expor e defender as questões da luta para outros segmentos sociais, ampliando-se assim a chance de obter novas alianças. O uso do espaço público remete sempre a uma sociedade democrática e à possibilidade de todos expressarem sua opinião. Na coluna à direita, preenchida com letras brancas, a população é chamada a participar de um ato com atividades variadas, como também a trazer camisetas para ser impressas e, desse modo, passar a divulgar a causa.

- A utilização na foto de elementos conhecidos e familiares ao movimento abre espaço para a interlocução. O recurso a argumentos "éticos e patéticos", que procuram a aprovação pelo lado emocional (Pinto, 2002, p.18), seduzindo pela compaixão ou indignação, acentua essa possibilidade: a foto é de forte apelo emocional, busca sensibilizar mostrando os horrores causados pela condição manicomial, pela situação de confinamento, humilhação e desumanidade.

- É a partir da fala dirigida aos leitores que o cartaz instaura seu lugar de poder, que não deixa dúvida quanto à pretensão: ter poder de lei. O slogan - palavra de ordem - inscrito num carimbo traz discursivamente para si esse poder. No entanto, o slogan do movimento, que imprimiria um sentido de oposição ao ambiente construído imageticamente, foi apresentado em formato de difícil leitura e apreensão, além de ocupar um espaço bem reduzido relativamente à imagem. O efeito é de enfraquecimento de sua presença e, consequentemente, de sua mensagem. Ainda por outro ângulo, se, pelo lado do ideário do movimento, o "cumpra-se" possa parecer 
desejável, ou até a única forma de se obter o desejado fim da política manicomial, por outro, imprime um tom impositivo. O resultado da estratégia de enunciação é que, por um lado, temos a presença imagética forte daquilo que se quer combater e, por outro, uma presença textual fraca e de caráter impositivo. É possível questionar a eficácia desse arranjo para os fins do movimento.

- No contraponto desse efeito impositivo, outros elementos apontam para uma busca de adesão à causa, de estímulo à participação ativa no evento. O cartaz convida para atividades variadas, solicita que as pessoas levem camisetas para ser decalcadas e pede que participem.

- Um efeito ainda a observar é o de força política e econômica, ao evidenciar os vários promotores institucionais e um apoiador.

\section{Cartaz 2}

- Pela ausência de textos mais informativos e explícitos, a intenção do material parece ter sido a de se dirigir a um público específico, que conhece o problema e o que está sendo feito para resolvê-lo. Outro elemento do dispositivo endossa essa hipótese: a metáfora do cadeado superposto às letras em degradé é de difícil entendimento para quem não tem contato anterior com o discurso antimanicomial. Se a intenção dos realizadores foi falar com os gestores e os profissionais da área da saúde e os donos de manicômios, provavelmente essa interlocução obteve algum grau de sucesso. Se a intenção foi incluir a população entre seus interlocutores, a comunicação teve dificuldade em se completar.

- Mesmo considerando um destinatário familiarizado com os signos do movimento antimanicomial, o dispositivo gráfico não é de fácil apreensão. A repetição da palavra "manicômio" em degradé no fundo e o cadeado semiaberto na frente com as palavras "nunca mais" configuram um arranjo gráfico que requer um grau elevado de abstração, dificultando o entendimento de grande parte das pessoas. O cadeado está aberto, aponta para uma nova situação. A palavra manicômio vai apagando-se, mostra que os manicômios vão extinguir-se. Não são elementos de fácil apropriação, exigem experiência anterior com esse tipo de representação. Como mostrou Araújo (2000), diante de elementos alheios ao contexto dos leitores, portanto, de difícil apropriação, aumenta-se a possibilidade de interpretações especulativas; o prévio compartilhamento do ideário do movimento minimiza um pouco essa dificuldade, mas não garante a interlocução.

- O fato de os sujeitos da enunciação serem representantes da sociedade civil organizada - um fórum de saúde mental e uma associação de usuários - e o apoio do CRP conferem mais legitimidade e um caráter mais político e menos institucional ao material.

\section{Intertexto e memória}

Os cartazes estudados fazem parte de uma coleção e se apresentam como objetos de um acervo que se quer preservar para que a história do movimento de luta antimanicomial 
não se perca e se inclua como parte da memória da saúde. A preservação de documentos da memória do movimento antimanicomial permite difundir informações sobre acontecimentos históricos no campo da saúde mental brasileira, tornando-o acessível às diferentes gerações e segmentos sociais. A valorização da história de luta de alguns movimentos sociais se vem constituindo como um compromisso político com a identidade desses grupos, além de uma forma de reparação com grupos que foram torturados e calados. Os materiais desse arquivo se inscrevem no espaço público competindo com outras narrativas, disputam sentido e divulgam informações sobre acontecimentos históricos que poderiam perder-se ou ser contados de outra perspectiva.

Assim, os cartazes nos conduzem por uma "rede infinita de remissivas de representações", como explica Araújo (2000, p.130), fazendo com que o sentido só consiga estabilidade provisoriamente. A imagem de pessoas subjugadas e humilhadas num local de grades e um cadeado pode ser associada aos hospícios ou outras instituições fechadas onde as pessoas recebem tratamento degradante e não têm contato com o exterior. Mas a degradação humana presente nessa imagem e na prática que ela representa não corresponde a um discurso já consolidado e hegemônico na sociedade. O movimento antimanicomial existe justamente porque esse discurso ainda é contra-hegemônico, embora sua situação no mercado simbólico dos discursos sobre a loucura tenha melhorado enormemente. A ideia de que os loucos deveriam ser isolados naturalizou-se na Modernidade; assim, os que não gozavam de razão não poderiam conviver numa sociedade em que a racionalidade era a ideia dominante. Não se pode esquecer, no entanto, que essa também é a época em que os direitos do homem se estabelecem; a exclusão deveria, então, estar respaldada. A ciência médica tratou de dar tal respaldo, e os loucos foram segregados para tratamento. O discurso da segregação dos loucos passou a circular e tornou-se natural. A sociedade assumiu tal discurso como verdadeiro e não se questionou mais sobre tais práticas. No século XX, o silêncio de outras práticas possíveis é rompido. Os atores sociais que se organizaram para melhorar as estruturas manicomiais rapidamente compreenderam que as estruturas são viciadas e pedem uma sociedade sem manicômios. A sociedade tem dificuldade de aceitar tal mudança, os atores sociais envolvidos na luta passam a mostrar os horrores ocorridos nos espaços manicomiais, salientam os aspectos prisionais e procuram aliados para sua causa. Esse contexto intertextual mostra como uma peça, como os cartazes analisados, entra num universo de disputas de sentido, e o modo como são organizadas suas estratégias discursivas (seus dispositivos de enunciação) poderá favorecer um ou outro discurso.

Ampliando o contexto intertextual dos cartazes, podemos dizer que eles estabelecem uma conversação com seus predecessores. No encontro de Bauru, marco do movimento, foi lançado o lema "Por uma sociedade sem manicômio", utilizado nos dez anos que separam o marco dos cartazes analisados em inúmeros outros eventos, ipsis literis ou com variações, mas sempre com o mesmo sentido. Conhece-se um cartaz argentino anterior que tem o mesmo slogan. As imagens são diferentes, mas o slogan é forte e repetido por diversos outros materiais ainda hoje. 


\section{O contexto textual (cotexto)}

Ampliando a rede intertextual, temos também os textos de circulação simultânea, que constituem um cotexto para os cartazes em análise. O cartaz 1, particularmente, guarda uma forte remissão a esse outro, de circulação imediatamente anterior, reproduzido abaixo (Figura 3). Outros cartazes de circulação simultânea colaboraram na criação de um conjunto de discursos circulantes que, de alguma forma, fortalecem as condições de concorrência discursiva de cada um. Como exemplo, temos um cartaz confeccionado pelos mesmos realizadores do grupo 2 (também reproduzido a seguir), que tem como slogan "Liberdade ainda que tam-tam" (Figura 4) e que circulou no mesmo espaço geográfico. Embora com dispositivo de enunciação diferenciado, integra possivelmente a rede semiótica em que os sentidos dos cartazes analisados se instituem.

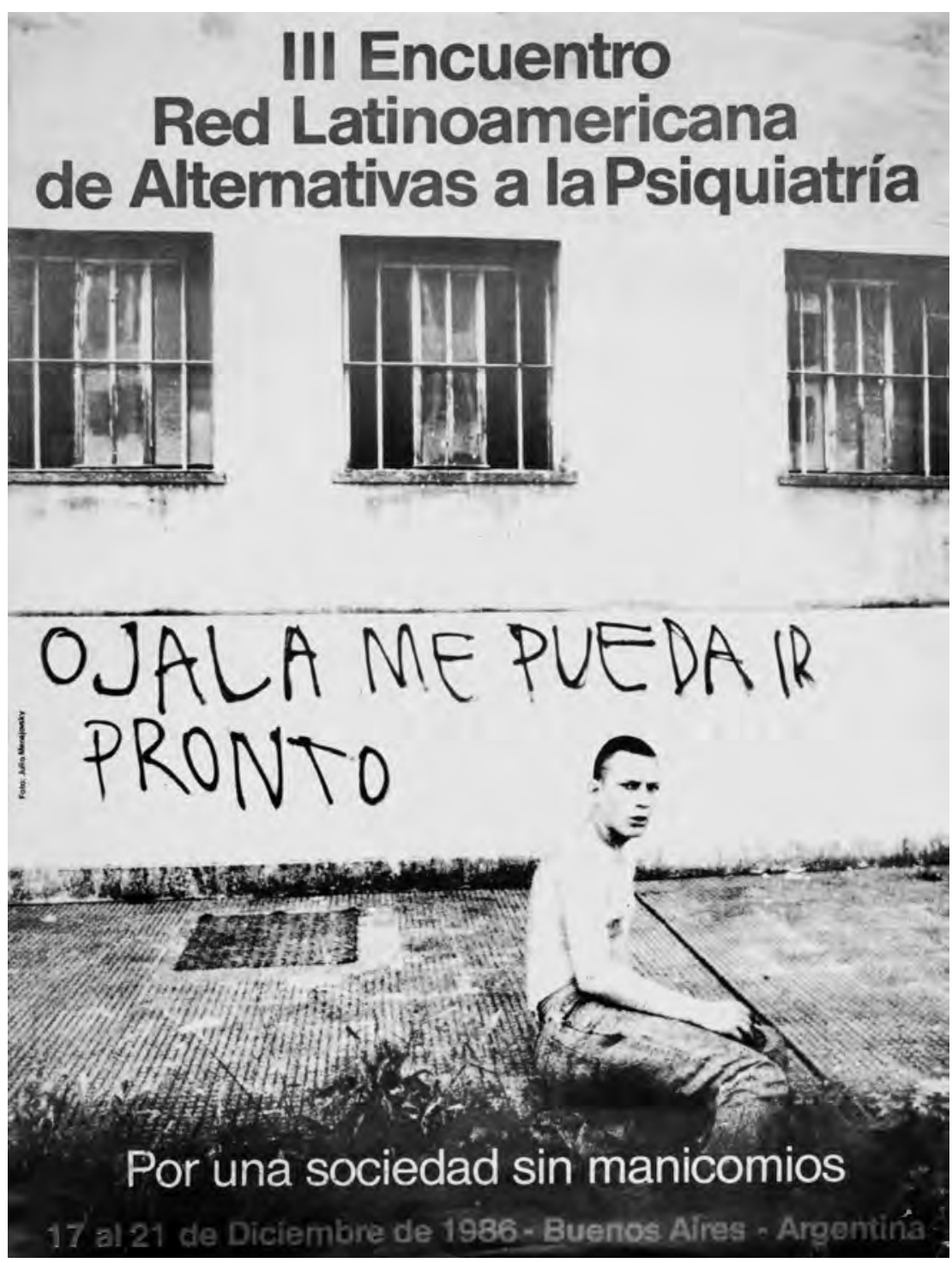

Figura 3: Fonte: Acervo Laps/Ensp/ Fiocruz. 


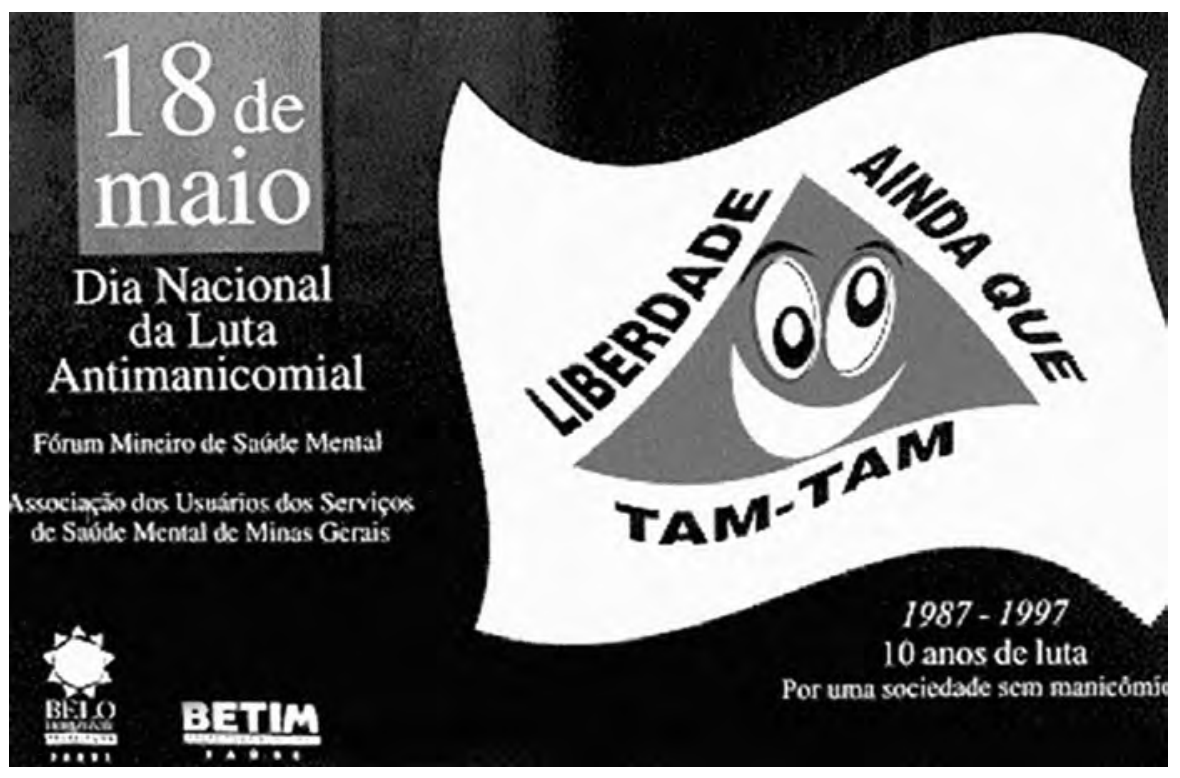

Figura 4: Fonte: Acervo Laps/ Ensp/Fiocruz.

\section{Considerações finais}

A análise do discurso dos dois cartazes comemorativos do Dia Nacional de Luta Antimanicomial permitiu-nos desvendar algumas das estratégias utilizadas pelos atores antimanicomiais para entrar no espaço público e disputar sentido com outros atores. As produções dos cartazes 1 e 2 são diferentes; enquanto no cartaz 1 ocorre a junção de forças que nem sempre trabalhavam em conjunto, as forças que se unem no cartaz 2 naquele momento não vivenciavam significativos conflitos ou disputas de poder. O discurso antagonista pró-instituição manicomial - aparece nos dois cartazes, sendo, em ambos, desqualificado. Apesar de empregarem a mesma tática e utilizarem o mesmo slogan, os cartazes foram produzidos para públicos diferentes e locais diversos e organizam suas estratégias discursivas de formas diferentes. E apesar de participarem de um mesmo movimento, não se apresentaram discursivamente da mesma forma, instaurando relações de poder diferenciadas.

As formas como os cartazes 1 e 2 são constituídos são formas de luta pelo poder simbólico, aqui observado pelo conceito de Bourdieu $(2009$, p.9) "poder de construção da realidade". A tentativa dos seus realizadores é obter adesões para sua causa, mas isso depende de uma série de variáveis - entre outras, a circulação e a forma de apropriação dos sentidos. A circulação é um elemento possível de aproximação, por envolver elementos concretos pragmáticos, mas a apropriação é uma grande incógnita, sendo totalmente contextual.

As forças relacionais estão em movimento. Araújo (2000, p.150) explica que "o centro é hegemônico, mas não é onipotente, tanto pela capacidade de reação e estratégias da periferia como pela luta interna que se desenvolve dentro de cada núcleo". Desse modo, posições que pareciam cristalizadas, como a dos pacientes alienados considerados incapazes de ocupar algum lugar de fala, modificam-se aos poucos, como produto dos embates discursivos e sociais. O lugar de segregação, considerado como lugar de tratamento e centro da ciência, perde paulatinamente seu lugar de verdade. Na dinâmica das posições de centro e periferia 
discursivos concretiza-se sempre a possibilidade de rompimento com o que era considerado cristalizado e estável, possibilidade formada por diversas circunstâncias, entre as quais a prática comunicativa que aqui, neste estudo, é representada pela produção e circulação de cartazes. Na disputa pelo poder simbólico, os campos se reorganizam e novos acordos são realizados. Os cartazes aqui analisados são parte desse movimento.

\section{NOTA}

${ }^{1}$ Declaramos que não houve conflito de interesses na concepção deste trabalho.

\section{REFERÊNCIAS}

AMARANTE, Paulo.

Saúde mental e atenção psicossocial. Rio de Janeiro: Editora Fiocruz. 2013.

AMARANTE, Paulo.

Loucos pela vida: a trajetória da Reforma

Psiquiátrica no Brasil. Rio de Janeiro: Serviço de Desenvolvimento Educacional/Escola Nacional de Saúde Pública Sergio Arouca. 1995.

ARAUJO, Inesita. S.

Mercado simbólico: interlocução, luta, poder: um modelo de comunicação para políticas públicas. Tese (Doutorado em Comunicação) Universidade Federal do Rio de Janeiro, Rio de Janeiro. 2002.

ARAUJO, Inesita. S.

A reconversão do olhar: prática discursiva e produção dos sentidos na intervenção social. São Leopoldo: EdUnisinos. 2000.

BAKHTIN, Mikhail.

Marxismo e filosofia da linguagem. São Paulo: Hucitec. 2006.

BOURDIEU, Pierre.

O poder simbólico. Rio de Janeiro: Bertrand Brasil. 2009.

ELKAIM, Mony (Ed.).

Réseau alternative à la psychiatrie. Paris: Union Générale d'Editions. 1977.

DESVIAT, Manuel.

A reforma psiquiátrica. Rio de Janeiro: Editora Fiocruz. 2008.

FOUCAULT, Michel.

A ordem do discurso. São Paulo: Loyola. 2009.

LANDOWSKI, Eric.

A sociedade refletida. São Paulo: Educ; Pontes. 1992.

MAIA, Rousiley C.M.; FERNANDES, Adélia B. O movimento antimanicomial como agente discursivo na esfera pública política. Revista Brasileira de Ciências Sociais, v.17, n.48, p.157-171. 2002.
MAINGUENEAU, Dominique.

Termos-chave da análise do discurso. Belo Horizonte: EdUFMG. 2006.

MAINGUENEAU, Dominique.

Novas tendências em análise do discurso. Campinas: Pontes; EdUnicamp. 1997.

NUNES, Edison; JACOBI, Pedro.

Movimentos populares urbanos, participação e democracia. In: Nunes, Edison; Jacobi, Pedro. Movimentos sociais urbanos, minorias étnicas e outros estudos. Brasília: Associação Nacional de Pós-graduação e Pesquisa em Ciências Sociais. p.25-62. 1983.

ORLANDI, Eni P.

Discurso e leitura. São Paulo: Cortez. 2008

PEIRCE, Charles S.

Semiótica. São Paulo: Perspectiva. 1977.

PINTO, Milon J.

Comunicação e discurso: introdução à análise do discurso. São Paulo: Hacker. 2002.

PINTO, Milton J.

As marcas linguísticas da enunciação: esboço de uma gramática enunciativa do Português. Rio de Janeiro: Numen. 1994.

PITTA, Ana M.F.

Um balanço da reforma psiquiátrica brasileira: instituições, atores e políticas. Ciência e Saúde Coletiva, v.16, n.12, p.45-79. 2011.

SANTORO FILHO, Antônio Carlos.

Direito e saúde mental à luz da lei 10.216 de 6 de abril de 2001. São Paulo: Verlu. 2012.

SCARCELLI, Ianni R.

Entre o hospício e a cidade: dilemas no campo da saúde mental. São Paulo: Zagodoni. 2011.

SOALHEIRO, Nina I.

Da experiência subjetiva à prática política: a visão do usuário sobre si, sua condição, seus direitos. Tese (Doutorado em Saúde Pública) - Escola Nacional de Saúde Pública Sergio Arouca, Fiocruz, Rio de Janeiro. 2003. 
VASCONCELOS, Eduardo Mourão.

Impasses políticos atuais do Movimento

Nacional de Luta Antimanicomial (MNLA)

e propostas de enfrentamento: se não nos

transformamos, o risco é a fragmentação e a

dispersão política. Cadernos Brasileiros de Saúde Mental, v.4, n.8, p.57-67. 2012.
VERÓN, Eliseo.

A produção de sentidos. São Paulo: Cultrix; EdUSP. 1980.

YASUI, Sylvio.

Rupturas e encontros: desafios da reforma psiquiátrica brasileira. Rio de Janeiro: Editora Fiocruz. 2010.

\section{$\rightarrow \rightarrow \rightarrow<<<$}

